\title{
Tıp Fakültesi Öğrencilerinin Hekimlik Değer Algıları
}

\section{Medical Profession Value Perceptions of Medical Students}

\author{
Selcen ÖNCت̈̈ (ORCID: 0000-0001-6329-4227) \\ Özlem EREL* (ORCID: 0000-0001-8920-1105) \\ *Aydın Adnan Menderes Üniversitesi Tıp Fakültesi Aydın, TÜRKIYE \\ Sorumlu Yazar: Selcen ÖNCÜ, E-Posta: selcenoncu@hotmail.com
}

\section{Özet}

Amaç: İyi bir hekim olmak ve hekimlik değerlerini kazanmak için mezuniyet öncesi tıp eğitimi büyük önem taşımaktadır. Çalışmamızda, Aydın Adnan Menderes Üniversitesi Tıp Fakültesi öğrencilerinin hekimlik mesleğini nasıl algıladıkları ve bu algıyı etkileyen etmenlerin belirlenmesi amaçlanmıştır.

Yöntem: Çalışmamız, Ekim 2019-Ocak 2020 tarihleri arasında Aydın Adnan Menderes Üniversitesi Tıp Fakültesi'nde eğitim görmekte olan öğrencilerle gerçekleştirilmiş, tanımlayıcı tipte bir araştırmadır. Çalışma 751 gönüllü öğrencinin katılımıyla gerçekleştirilmiştir. Veri toplamada kullanılan anket formu; kişisel bilgilerin ve bir adet açık uçlu sorunun yer aldığı ilk bölüm ile Gökler ve ark.ları tarafından 2017 yılında geliştirilen Hekimlik Değer Algısı (HDA) Ölçeğinden oluşmaktadır. Ölçek; 3 alt boyuttan (hekim tutumu, hasta hekim ilişkisi, hekimin empati yeteneği) ve 18 olumlu maddeden oluşan 5'li Likert olarak hazırlanmıştır. Veri analizinde gruplar arası karşılaştırmalarda değişkenler normal dağılım göstermediği için Mann Whitney U ve Kruskall Wallis testleri kullanılmıştır.

\section{Anahtar sözcükler: \\ Hekimlik, İyi Hekim, \\ Tıp Fakültesi \\ Öğrencileri, Alg1}

Keywords:

Medical Profession, Good Doctor, Medical Students, Perception

Gönderilme Tarihi

Submitted: 04.03.2021

Kabul Tarihi

Accepted: 26.04.2021

Bulgular: Yaşları 18-29 yıl (ortalama $20.36 \pm 0.07$ ) arasında değişmekte olan katılımcıların \%47,4'ü kadın; 41,5'i birinci, \%18,8 ikinci, \%15,4 üçüncü, $\% 7,6$ dördüncü, $\% 12,6$ beşinci, $\% 4$ altıncı sınıftı. HDA ölçeğinden alınan ortalama puan 79.56 7.2 (27-90); tutum puanı $36.88 \pm 3.4$ (10-40); ilişki puanı 22.27 \pm 2.2 (7-25); empati puanı 15.61 \pm 3.0 'dır (6-20). Kadın katılımcıların tutum alt boyut puan1 $37.25 \pm 3.1(\mathrm{p}=0,009)$, erkeklerin empati alt boyut puanı $15.24 \pm 2.9(\mathrm{p}=0,00)$ anlamlı olarak yüksek bulunmuştur. Sınıflar arası farklılık istatistiksel olarak anlamlı bulunmuştur $(\mathrm{p}<0,001)$. HDA puanı 1. sınıflarda yüksek iken 3. sınıfa doğru azalmış, 4. sınıfta yeniden yükselmiştir. Akademik başarı algısı yükseldikçe HDA ortalama puanın anlamlı olarak arttığ 1 ( $=0.003)$ tespit edilmiştir. Katılımcıların "İyi bir hekim nasıl olmalıdır?” sorusuna verdikleri ilk üç yanıt; bilgili $(\% 31,2)$, iyi iletişim becerilerine sahip (\%23,7), sabırlı (\%20) olarak belirlenmiştir.

Sonuç: HDA ve alt boyutların tümünde en yüksek puanların birinci sınıflara, en düşük puanların ise üçüncü sınıflara ait olduğu saptanmıştır. Akademik başarı algısı yüksek olan öğrencilerin HDA puanları da yüksek bulunmuştur.

\section{Abstract}

Aim: Undergraduate medical education has great importance to be a good doctor and to gain medical values. In our study, we aimed to determine how the students of Aydin Adnan Menderes University Faculty of Medicine perceive the medical profession and the factors affecting this perception.

Künye: Öncü S, Erel Ö. Tıp Fakültesi Öğrencilerinin Hekimlik Değer Algıları Tip Egitimi Dunyasi. 2021;20(61):98-105 
Methods: Our descriptive study was carried out on students studying at Aydin Adnan Menderes University Faculty of Medicine. The study was carried out with the participation of 751 volunteer students. The first part of the questionnaire included personal information and one open-ended question, the second part included the Medical Value Perception Scale (MPVS) developed by Gökler et al. (2017). The Scale consisted of 3 sub-dimensions (physician attitude, patient-physician relationship, physician's empathy ability) and 18 positive items with 5-point Likert. In the data analysis, Mann Whitney $U$ and Kruskall Wallis tests were used.

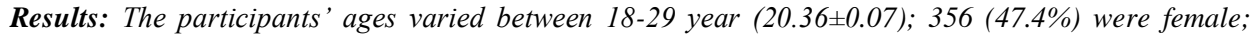
$41.5 \%$ were first, $18.8 \%$ second, $15.4 \%$ third, $7.6 \%$ fourth, $12.6 \%$ fifth and $4 \%$ were sixth grade. The mean score obtained from the MPVS was $79.56 \pm 7.2$ (27-90); attitude score 36.88土3.4 (10-40); doctor's

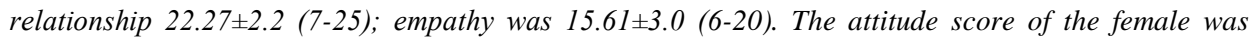
$37.25 \pm 3.1$ ( $p=0.009)$, the empathy score for the males was $15.24 \pm 2.9(p=0.00)$. The difference between the classes was statistically significant ( $p<0.001)$. The MPVS was high in the first grade; it decreased towards the third and increased in the fourth grade. The average score of MPVS increased significantly $(p=0.003)$ as the perception of academic achievement increased. The participants first three answers for "How should a good doctor be?" were; knowledgeable (31.2\%), with good communication skills (23.7\%), patient (20\%).

Conclusions: In all MPVS and sub-dimensions, first grades got the highest scores, and third grades got the lowest scores. MPVS scores of participants with high academic achievement perception were high.

\section{GíRiş}

İnsanlık tarihi kadar eskilere dayandığı bilinen hekimlik mesleği, insan vücuduna girerek hastalık yaptığı düşünülen kötü ruhları danslar ve bitkiler ile kovarak başlamış, uzun süre ustaçırak ilişkisi ile devam etmiş, hastaneler ve üniversitelerde verilen tıp eğitimleri ile gelişerek günümüze kadar gelmiştir (1). Günümüzde, Dünya Tıp Eğitimi Federasyonu (WFME) tıp eğitiminin amacını "hasta ve toplum için kaliteli, koruyucu ve tedavi edici hizmet vermeyi sağlayan, bilgi, beceri, değerler ve davranış biçimlerinde yetenekli ve yeterli olan hekimleri yetiştirmek" olarak tanımlamaktadır (2).

İyi hekimlik farklı dönemlerde farklı nitelikler ile tanımlanmış olsa da iyi hekimden beklenen nitelikler genelde benzerdir. Dünya Hekimler Birliği 1988 Edinburgh Bildirgesi ile toplumun sağlık düzeyini yükseltecek hekimler tanımını ortaya koyarken, Genel Tip Konseyi (1993) iletişim becerileri ve klinik becerilerde yetkin, Dünya Sağlık Örgütü (1996) "Beş Yıldızlı Doktor" kavramı ile hizmet sunucu, karar verici, iletişimci, toplum lideri ve yönetici hekim niteliklerini vurgulamıştır $(3,4)$.
Ülkemizde ise benzer nitelikler, 2020 yılında güncellenen Ulusal Çekirdek Eğitim Programında bir tıp fakültesi mezununun mesleki uygulamalar; mesleki değerler ve yaklaşımlar, mesleki ve bireysel gelişim alanlarında yetkin olmasının beklendiği belirtilerek bu alanlara ait yetkinlikler belirtilmiştir (5).

Tıp eğitimi insanla uğraşmanın verdiği dikkat ve usta çırak gibi deneyim aktarımını içeren farklı bir eğitime sahiptir. Hekimlik tutum ve davranışları, bireysel özellikler ve hekimlik eğitimi etkisiyle oluşmaktadır. Hekimlerin hekimlik değer algısı kazanmaları, tıp eğitimi döneminde olmaktadır. Çalışmamızda, Tıp Fakültesi öğrencilerinin hekimlik mesleğini nasıl algıladıkları ve bu algıyı etkileyen etmenlerin belirlenmesi amaçlanmıştır.

\section{GEREÇ VE YÖNTEM}

Çalışmamız, Ekim 2019 - Ocak 2020 tarihleri arasında Aydın Adnan Menderes Üniversitesi Tip Fakültesi'nde eğitim görmekte olan öğrenciler ile gerçekleştirilmiş, tanımlayıcı tipte bir araştırmadır. Çalışmada örneklem seçimine 
gidilmemiş olup çalışma 751 gönüllü öğrencinin katılımıyla gerçekleştirilmiştir. Veriler; sözlü onamları alınan katılımcılardan yüz yüze anket yöntemi ile toplanmıştır. Araştırmacılar tarafından hazırlanan veri toplama formu; kişisel bilgilerin ve bir adet açık uçlu sorunun yer aldığ 1 ilk bölüm ile Gökler ve ark. tarafından 2017 yılında geliştirilerek geçerlik ve güvenirliği saptanmış Hekimlik Değer Algısı (HDA) Ölçeğinden oluşmaktadır. Ölçek; hekim tutumu ( 8 madde), hasta hekim ilişkisi (6 madde), hekimin empati yeteneği (4 madde) olarak 3 alt boyuttan ve 18 olumlu maddeden oluşan 5'li likert olarak hazırlanmıştır. Ölçekten alınabilecek puanlar 18 ile 90 arasında değişmekte olup, maddeler "tamamen katıliyorum" 5, "katılıyorum" 4, "kararsızım" 3, "katılmıyorum" 2 ve "kesinlikle katılmıyorum" 1 puan olarak puanlanmakta ve ölçeğin kestirim puanı bulunmamaktadır. Ölçek ile belirlenen HDA puan ortalaması hesaplandığında (minimum 18- maksimum 90), HDA puan ortalaması arttıkça, kişinin hekimlik değer algısının daha olumlu olduğu kabul edilmiştir. Ölçekten alınan puanlar ortalama \pm standart sapma olarak gösterilmiştir (6). Veri analizinde tanımlayıcı istatistikler, $\mathrm{T}$ testi, gruplar arası karşılaştırmalarda ise normal dağılım göstermediğinden Mann Whitney U ve
Kruskall Wallis testleri kullanıldı. İstatistiksel anlamlılık düzeyi olarak $\mathrm{p} \leq 0.05$ kabul edilmiştir. HDA Ölçeğinin kullanımı için eposta yolu ile izin alınmıştır. Araştırmanın uygulanabilmesi için gerekli etik kurul onayı T.C. Aydın Adnan Menderes Üniversitesi Rektörlüğü Tıp Fakültesi Dekanlığı Girişimsel Olmayan Klinik Araştırmalar Etik Kurulu'ndan (Protokol No:2019/151) alınmıştır.

\section{BULGULAR}

Yaşları 18-29 (ortalama $20.36 \pm 0.07$ ) arasında değişmekte olan 751 katılımcının 395'i $(\% 52,6)$ erkek, 356's1 $(\% 47,4)$ kadın idi. Sinıf dağılımlarına bakıldığında; 312'si (\%41,5) 1. sinif, 141'i (\%18,8) 2. sinif, 116's1 (\%15,4) 3. sinif, 57'si (\%7,6) 4. sinif, 95'i (\%12,6) 5.sinif, 30'u (\%4) 6. sınıf idi. Öğrencilerin 186's1 $(\% 24,8)$ akademik başarısını iyi, 475'i $(\% 63,2)$ orta, 90’1 (\%12) ise kötü olarak algıladığını belirtmiştir. Ailesinde sağlık çalışanı olduğunu bildiren öğrenci sayısı; $235(\% 31,3)$ idi. HDA ölçeğinden alınan ortalama puan 79.56 7.2 (2790 arasında) olarak belirlenirken alt boyutlardan tutum puanı ortalama $36.88 \pm 3.4 \quad(10-40$ arasında); ilişki puanı 22.27 $\pm 2.2 \quad$ (7-25 arasında); empati puanı 15.61 $\pm 3.0 \quad$ (6-20 arasında) saptanmıştır (Tablo 1).

Cinsiyet değişkeninde; kadınlarda tutum alt

Tablo 1. Cinsiyete Göre HDA Ortalama ve Alt Boyut Puanları

\begin{tabular}{lcccc}
\hline & $\begin{array}{c}\text { HDA } \\
\text { Puanı } \pm \text { ss }\end{array}$ & $\begin{array}{c}\text { Hekim Tutumu } \\
\text { Alt Boyut } \\
\text { Puanı } \pm \text { ss }\end{array}$ & $\begin{array}{c}\text { Hasta Hekim } \\
\text { ilişkisi } \\
\text { Alt Boyut } \\
\text { Puanı } \pm \text { ss }\end{array}$ & $\begin{array}{c}\text { Hekim Empatisi } \\
\text { Alt Boyut } \\
\text { Puanı } \pm \text { ss }\end{array}$ \\
\hline Ortalama & $\mathbf{7 9 , 5 6 \pm 7 , 2}$ & $\mathbf{3 6 , 8 8} \pm \mathbf{3 , 4}$ & $\mathbf{2 2 , 2 7 \pm \mathbf { 2 , 2 }}$ & $\mathbf{1 5 , 6 1 \pm 3 , 0}$ \\
\hline Kadın & $79,69 \pm 6,8$ & $37,25 \pm 3,1$ & $22,37 \pm 2,0$ & $15,24 \pm 3,0$ \\
\hline Erkek & $79,44 \pm 7,6$ & $36,55 \pm 3,6$ & $22,18 \pm 2,3$ & $15,95 \pm 3,0$ \\
\hline
\end{tabular}

boyut puanı (ortalama 37.25 \pm 3.1$) \quad(p=0.009)$ erkeklerde ise empati alt boyut puanı (ortalama $15.24 \pm 2.9)$ anlamlı olarak yüksek $(\mathrm{p}=0.00)$ bulunmuştur (Tablo 1). Sınıf değişkenine göre HDA ortalama puanı ve tüm alt boyutlarda anlamlı farklılık tespit edilmiştir $(\mathrm{p}=0.00)$. HDA ve alt boyut puanlarının en yüksek olduğu sınıf 1. sınıf iken puanlar 3. sınıfa doğru düşmekte, 4. sınıfta yeniden yükselmekte, beşinci sınıfta düşmektedir (Tablo 2). 
Tablo 2. Sinıflara Göre HDA Ortalama ve Alt Boyut Puanları

\begin{tabular}{lcccc} 
Sınıf & $\begin{array}{c}\text { HDA Puanı } \\
\text { Ort. } \pm \text { ss }\end{array}$ & $\begin{array}{c}\text { Hekim Tutumu } \\
\text { Puanı } \\
\text { Ort. } \pm \text { ss }\end{array}$ & $\begin{array}{c}\text { Hasta Hekim } \\
\text { Ilişkisi Puanı } \\
\text { Ort. } \pm \text { ss }\end{array}$ & $\begin{array}{c}\text { Hekim Empatisi } \\
\text { Puanı } \\
\text { Ort. } \pm \text { ss }\end{array}$ \\
\hline Bir & $81,40 \pm 6,6$ & $37,42 \pm 3,1$ & $22,69 \pm 2,1$ & $16,41 \pm 2,9$ \\
\hline İki & $79,56 \pm 8,1$ & $36,72 \pm 3,9$ & $22,35 \pm 2,4$ & $15,68 \pm 3,0$ \\
\hline Üç & $77,08 \pm 6,4$ & $36,18 \pm 3,1$ & $21,90 \pm 1,9$ & $14,28 \pm 3,0$ \\
\hline Dört & $79,39 \pm 7,1$ & $36,63 \pm 3,1$ & $22,46 \pm 2,0$ & $15,54 \pm 3,1$ \\
\hline Beş & $77,47 \pm 7,3$ & $36,60 \pm 3,7$ & $21,35 \pm 2,2$ & $14,86 \pm 2,8$ \\
\hline Altı & $77,50 \pm 7,1$ & $36,23 \pm 3,5$ & $21,67 \pm 2,5$ & $14,87 \pm 2,6$
\end{tabular}

HDA ortalama puanının akademik başarı algısı ile orantılı olarak artışı istatistiksel olarak anlamlı bulunmuştur ( $\mathrm{p}=0.003)$ (Tablo 3).

Tablo 3. Akademik Başarı Algısına Göre HDA Ortalama ve Alt Boyut Puanları

\begin{tabular}{lcccc}
\hline $\begin{array}{l}\text { Akademik } \\
\text { Başarı } \\
\text { Algısı }\end{array}$ & $\begin{array}{c}\text { HDA Puanı } \\
\text { Ortalama } \pm \text { ss }\end{array}$ & $\begin{array}{c}\text { Hekim Tutumu } \\
\text { Puanı } \\
\text { Ortalama } \pm \text { ss }\end{array}$ & $\begin{array}{c}\text { Hasta Hekim } \\
\text { Ilişkisi Puanı } \\
\text { Ortalama } \pm \text { ss }\end{array}$ & $\begin{array}{c}\text { Hekim Empatisi } \\
\text { Puanı } \\
\text { Ortalama } \pm \text { ss }\end{array}$ \\
\hline Kötü & $78,47 \pm 7,7$ & $36,44 \pm, 7$ & $22,31 \pm 2,2$ & $14,95 \pm 3,2$ \\
\hline Orta & $79,22 \pm 7,0$ & $36,80 \pm 3,2$ & $22,19 \pm 2,1$ & $15,47 \pm 3,0$ \\
\hline İyi & $80,95 \pm 7,3$ & $37,31 \pm 3,5$ & $22,48 \pm 2,2$ & $16,31 \pm 2,9$ \\
\hline
\end{tabular}

Ölçek maddelerinin frekansları incelendiğinde en olumlu maddelerin "hasta hekim ilişkisi" ve "hekim tutumu" alt boyutlarında olduğu belirlenmiştir. Etkili iletişim becerilerine sahip ve bilgili olmak iyi hekimlik için en olumlu nitelikler arasında görülmüştür (Tablo 4).

"İyi bir hekim nasıl olmalıdır?" açık uçlu sorusuna katılımciların verdikleri yanitlar incelenerek alt gruplara ayrilarak ortak nitelikler gruplandırılmışıtır. İyi hekimde beklenen nitelikler; (katılımcıların yantları puanlarına göre sıralandığında) bilgili (n:234, $\% 31$ ), iyi iletişim becerilerine sahip (n:178, \%24), sabırlı (n:152, \%20), anlayışlı (n:91,5, $\% 12$ ), saygılı (n:80, \%11), çalışkan (n:77, \%10), etik (n:77, \%10), dürüst (n:69, \%9), güvenilir (n:65, \%9) ve yardımsever (n:54, \%7) olarak sıralanmıştır (Şekil 1). 
Tablo 4. HDA Ölçeği Madde Frekansları

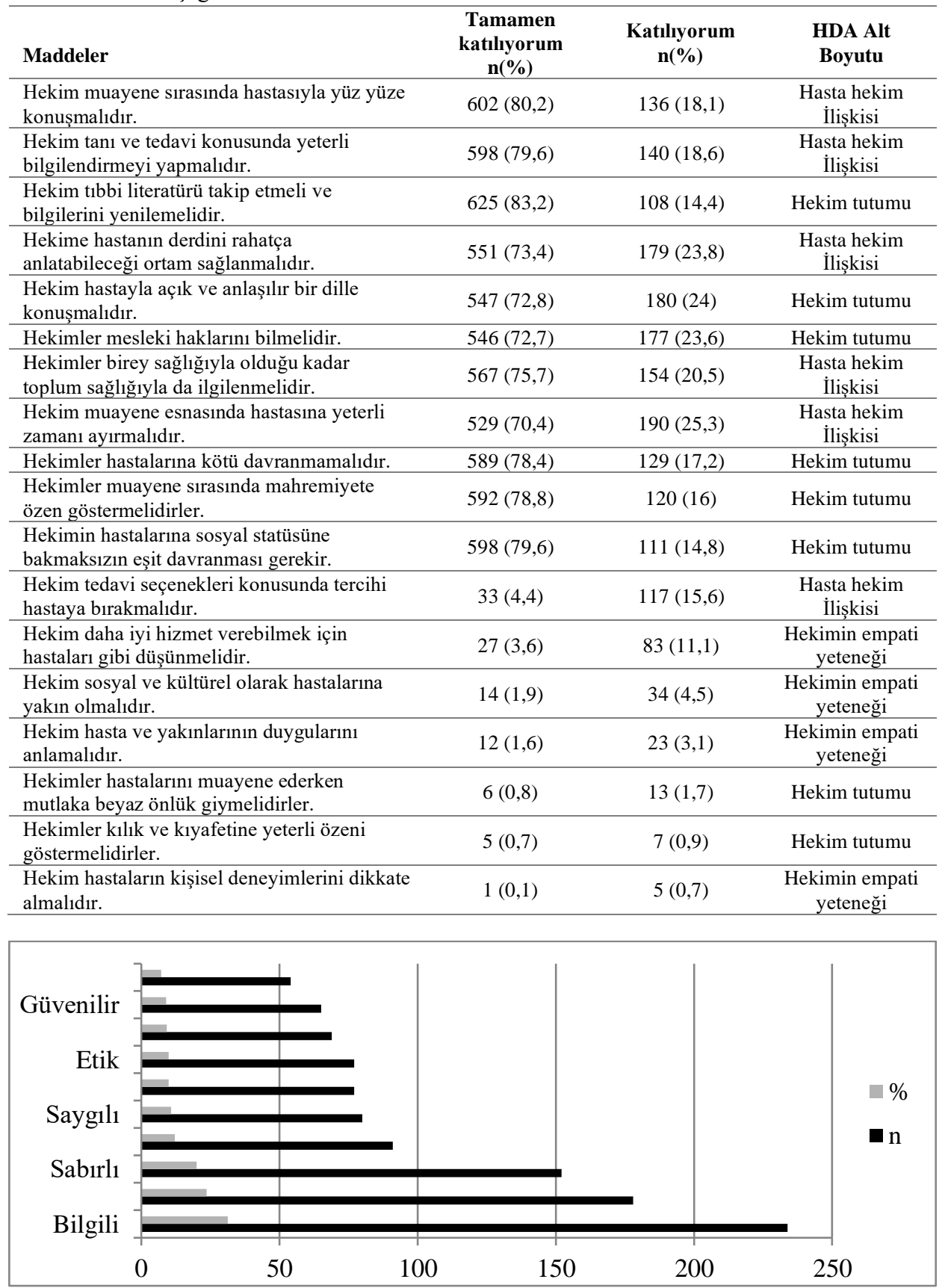

Şekil 1. İyi Hekimden Beklenen Nitelikler 


\section{TARTIŞMA}

Hekimlik mesleğinin ilk aşaması olan mezuniyet öncesi tıp fakültesi eğitimi, mesleki bilgi ve beceri yanında mesleki değer ve tutumların da kazanılmasının amaçlandığı uzun ve zorlu bir eğitim sürecidir. İyi hekimler yetiştirmek için sürecin her aşamasında hekimlik değer algısının geliştirilmesi önemlidir.

Gökler ve ark. (2017) çalışmasında HDA puan ortalaması 78.5 \pm .3 , (ortanca:80,0) iken bizde de benzer şekilde ortalama 79.56 \pm 7.2 , (ortanca:80,0) olarak saptanmıştır. HDA alt boyut ortanca değerlerine bakıldığında; hekim tutumu alt boyutunda:37,5, hasta hekim ilişkisinde:27,0, hekim empatisi alt boyutunda: 15,0 ; bizim çalışmamızda ise hekim tutumu alt boyutunda:38, hasta hekim ilişkisi alt boyutunda:23,0, hekim empatisi alt boyutunda:16,0 olarak saptanmıştır. Kadınlarda:81,0, erkeklerde:79,0 olan HDA ölçeği puan ortancaları çalışmamızda da benzer şekilde kadınlarda:81,0, erkeklerde:80,0 olarak saptanmıştır (6).

Öcal ve ark. (2018) Eskişehir Osmangazi Üniversitesi (ESOGÜ) Tip Fakültesi Hastanesine başvuran 405 hastanın hekimlik değer algılarına bakışlarını çalışmamızda kullandığımız ölçek ile değerlendirmişlerdir. Çalışmada HDA puan ortalamasının 82.62 olduğunu ve katılımcıların büyük ölçüde olumlu değer algıları yönünde yığılım gösterdiklerini saptamıştır. Orta ve ileri yaşta, erkeklerde ve öğrenim düzeyi düşük olanlarda HDA puanının daha yüksek olduğu belirlenmiştir (7).

Gökler ve ark. (2017) çalışmasında üçüncü sınıf öğrencileri HDA Ölçeğinden yüksek, birinci ve altınc1 sınıf öğrencileri daha düşük puan almışlardır, bizim çalışmamızda farklı olarak birinci sınıfların puanlarının diğer tüm sınıflardan anlamlı olarak yüksek, üçüncü sınıflarınki ise düşük bulunmuştur. Çalışmamızda akademik başarısının yüksek olduğunu düşünen öğrencilerin HDA puanlarının yüksek olması yine aynı çalışmada başarılı öğrencilerin puanlarının yüksek olması ile uyumludur (6).

Neumann ve ark.nın (2013) 1990-2010 y1lları arasında ögrencilerin empati becerileri ile ilgili yaptıkları sistematik çalışmasında incelenen 11 çalışmanın onunda tıp fakültesi öğrencilerinin ilk hasta ile temasının olduğu üçüncü sınıf ile birlikte empati düzeylerinin anlamlı olarak düştüğü bildirmiştir (8). Hojat ve ark.nın (2009) çalışmasında da tıp fakültesi öğrencilerinde okulun ilk iki yılında empati değerleri yüksek iken üçüncü sınıfta hasta teması ile birlikte empati değerlerinde istatistiksel olarak anlamlı olan ani bir düşüş gözlendiği bildirilmiştir (9) Çalışmamızda da benzer şekilde öğrenciler fakültenin ilk yılında yüksek HDA ortalama ve alt grup puanlarına sahip iken hasta ve klinik temasın olduğu üçüncü sınıfta puanların aniden düştüğü, dördüncü sınıfta hafif yükseldiği fakat asla birinci sınıftaki düzeye ulaşamadığı görülmüştür. Tıp fakültesine genelde insanlara yardım etmek, iyi bakmak gibi idealler ve insancil bir ruh hali ile giren ögrenciler zaman içinde eğiticileri, kliniklerde temas ettikleri hekimler, asistan hekimler ve hastaların etkisinde kalmaktadırlar. Öğrencilerin idealleri ve kendi değerleri ile kampüste klinik ortamlarda öğretilen açık veya örtülü mesajlar çok farklılık gösterebilmektedir (9).

Swing (2007) ile Monrouxe ve ark. (2011) çalışmalarında tıp fakültesi öğrencilerinde profesyonel değerlerin tıp fakültesine başladıktan sonra zaman içinde kendini yansıtma, deneyim ve keşif yoluyla geliştiğini göstermiş̧ir $(10,11)$. Reimer ve ark.(2019) ise bu çalışmalardan farklı olarak tıp fakültesinin ilk yıllarında profesyonel kimlik oluşum sürecine odaklanmıştır (12). Çalışmamızda da Reimer ve ark. nın çalışmasına benzer şekilde ögrencilerin ilk yıllarda HDA puanlarının yüksek olması dikkat çekmektedir.

Silveira ve ark. (2019) çalışmalarında, öğrencilerin tıp fakültesine başladıklarında ideal hekimlik niteliklerine sahip olduğunu düşündükleri ve rol model aldıkları eğiticilerinin kliniklerde ve kampüste 
düşündüklerinin tam tersine hastalar ve öğrenciler ile etkileşimlerinde saygı ve empati eksikliğinin olması ve eğiticiler tarafından geri plana itilmek eğiticilerini olumsuz rol modeller haline getirebildiğini savunmaktadır. Eğiticiler ile öğrencilerin uyumsuzluğu ve etkili iletişim kuramamalarının öğrencilerde siminizm savunma mekanizmalarını tetikleyerek zamanla duyarsız ve empatisi azalmış, depresif düşüncelere sahip, tükenmiş bireyler haline getirerek hekimlik ile ilgili algılarını olumsuz etkileyebileceğini bildirmektedir

Çalışmamızda da birinci sınıfta çok olumlu hekimlik değer algıları ile başlayan öğrencilerin zaman içinde algılarının olumsuzlaşması bu nedenle açıklanabilir.

Çalışmamızda hekim adaylarının bir hekimden bekledikleri en önemli özelliğin hekimin hastası ile yüz yüze konuşarak iletişim kurması olarak belirlenmiştir. HDA ölçeğinde yer alan "Hekim muayene sirasında hastasıyla yüz yüze konuşmalıdır" maddesi \%98,3 frekans ile en olumlu görülen maddedir. Bu özelliğin Öcal ve ark.'nın Eskişehir'de hastalar ile yaptıkları çalışma ile benzer $(\% 99,3)$ olduğu görülmüştür. Aynı çalışmada yine çalışmamız ile benzer şekilde hastaların da $(\% 98,5)$ çalışmamızdaki hekim adayları ile $(\% 98,3)$ hekimin tan 1 ve tedavi konusunda hastayı yeterince bilgilendirmesi gerektiğini düşünmektedir (7). Hurwitz ve ark. (2013) çalışmasında tıp fakültesi öğrencileri bir hekimde bulunmasını bekledikleri nitelikler arasında en önemlileri olarak; empati, hekim olmakta istekli, etkili sözlü iletişim, etik olmak, doğruluk ve dürüstlüğü saymışlardır. Hekimden beklenen nitelikler ile ilgili yapılan farklı çalışmalarda da empati ve sabır en önemli nitelikler arasında tanımlanmıştır (7, 8, 13-15).

Çalışmamızda da benzer şekilde etkili iletişim becerilerine sahip olmak, sabırlı olmak ve anlayışı olmak gibi değerler en istenilen nitelikler arasında yer almaktadır.

\section{SONUÇ}

Tıp fakülteleri kapsamlı eğitim programları ile mezunlarını bilgi ve beceriler ile donatmayı amaçlarken, mesleki değerleri önemseyen, iyi iletişim becerilerine sahip, olumlu hekimlik değer algıları olan iyi hekimler yetiştirmek de büyük önem taşımaktadır.

Çalışmamızda tıp fakültesi öğrencilerinin ölçek ve açık uçlu soruya verdikleri yanıtlar incelendiğinde; hekimlerde en çok "iyi iletişim becerileri” ve "bilgili olmak" özelliklerini bekledikleri görülmüştür.

Ölçekte öğrencilerin en olumlu yanıtlar verdikleri maddelerin; hekimin muayene sırasında hastasıyla yüz yüze konuşması, hastasına yeterli bilgilendirmeyi yapması ve literatürü takip ederek bilgilerini yenilemesi olarak sıralanmakta olduğu görülmüştür. $\mathrm{Bu}$ maddeler "hasta hekim ilişkisi" ve "hekim tutumu" alt boyutuna ait maddelerdir.

Akademik başarı algısı yüksek olan öğrencilerde hekimlik değer algısı daha yüksek saptanmıştır.

HDA ve alt boyutların tümünde birinci sınıfların en yüksek puanları alması üçüncü sınıfların ise en düşük puanları almaları sınıflar arası anlamlı farklılıklara neden olmuştur. Çalışmamızda dördüncü ve altıncı sınıfa ait temsiliyetin az olması çalışmanın kısıtlılığı olarak görülebilir.

Tıp fakültesine belli idealler ve hayaller ile geldiklerinde hekimlik değer algıları yüksek olan öğrencilerin değer algılarının yüksek tutulabilmesi için mezuniyet öncesi tıp eğitiminde, hasta hekim ilişkisi, empati yeteneği ve hekimlik tutumunu geliştirebilecek kuramsal ve uygulamalı derslere, etkinliklere yer verilmesi önemlidir. Bunun yanında, eğiticilerin öğrenciler için olumlu birer rol model olmaları yönünde desteklenmeleri ve motive edilmeleri önem taşımaktadır. Tıp fakültesi öğrencilerinin hekimlik değer algılarını etkileyebilecek konular araştırılarak bu konuda kapsamlı çalışmalar yapılmasının önemli olduğu düşüncesindeyiz. 
Tıp fakültelerinden mezun olacak hekimlerin mesleğini seven, severek yapan, iletişim becerileri, empati yetenekleri ve hekimlik tutumları yüksek iyi hekimler olarak yetiştirilmeleri hekimlik mesleğinin kalitesini artırarak tıp fakültelerinin mezuniyet hedeflerine ulaşmasını sağlayacaktır.

\section{KAYNAKLAR}

1. Gourevitch D. The history of medical teaching. The Lancet. 1999;354: SIV33.

2. Metcalfe D. The Edinburgh Declaration. Oxford University Press; 1989.

3. Council G. Tomorrow's doctors: recommendations on undergraduate medical education. London: GMC. 1993.

4. Antezana FS, Chollat-Traquet CM, Yach D. Health for all in the 21st century. World health statistics quarterly Rapport trimestriel de statistiques sanitaires mondiales. 1998;51(1):36.

5. Ulusal ÇEP-2020 U, Ulusal ÇEP-2020 U, Ulusal ÇEP-2020 D. Medical Faculty- National Core Curriculum 2020. Tıp Eğitimi Dünyası. 2020; 19(57- 1): 1-146.

6. Gökler ME, Öz F, Metintaş S. Hekimlik Değer Algısı Ölçeğinin güvenilirlik ve geçerliliğinin tıp fakültesi öğrencilerindeki sonuçları. Turkish Journal of Public Health. 2017;15(1):26.

7. Öcal EE, Aygüzer C, Dereli FE, Erbil S, Güneri B, Işık ST, et al. Eskişehir Osmangazi Üniversitesi Tıp Fakültesi Hastanesine Başvuran Hastalarda Hekimlik Değer Algılarına Bakışın Değerlendirilmesi. Türk Dünyası Uygulama ve Araştırma Merkezi Halk Sağlığı Dergisi. 2018;3(2):28-39
8. Neumann M, Edelhäuser F, Tauschel D, Fischer MR, Wirtz M, Woopen C, et al. Empathy decline and its reasons: a systematic review of studies with medical students and residents. Academic medicine. 2011;86(8):9961009.

9. Hojat M, Vergare MJ, Maxwell K, Brainard $\mathrm{G}$, Herrine SK, Isenberg GA, et al. The devil is in the third year: a longitudinal study of erosion of empathy in medical school. Academic Medicine. 2009;84(9):1182-91.

10. Swing SR. The ACGME outcome project: retrospective and prospective. Medical teacher. 2007;29(7):648-54.

11. Monrouxe LV, Rees CE, Hu W. Differences in medical students' explicit discourses of professionalism: acting, representing, becoming. Medical education. 2011;45(6):585602 .

12. Reimer D, Russell R, Khallouq BB, Kauffman C, Hernandez C, Cendán J, et al. Preclerkship medical students' perceptions of medical professionalism. BMC medical education. 2019;19(1):1-9.

13. Hurwitz S, Kelly B, Powis D, Smyth R, Lewin T. The desirable qualities of future doctors - A study of medical student perceptions. Medical Teacher. 2013;35(7): e1332-e9.

14. Kearney RA. Defining professionalism in anaesthesiology. Medical education. 2005;39(8):769-76.

15. Lambe P, Bristow D. What are the most important non-academic attributes of good doctors? A Delphi survey of clinicians. Medical teacher. 2010;32(8): e347-e54. 